\title{
Massacre dos Kaingang em Pitanga - PR, um conflito atrelado à ideologia do branqueamento e à expansão do capital sobre os territórios indígenas
}

\author{
Slaughter of the Kaingang Indians in the city of Pitanga - $P R$, a related conflict with the \\ ideology of whitening and the expansion of capital on indigenous territories
}

\author{
Cleverson Gonçalves* \\ Nilson Cesar Fraga** \\ Mateus Galvão Cavatorta***
}

\begin{abstract}
Resumo:
As primeiras décadas do século XX foram de extrema importância para a formação do atual tecido social brasileiro, este período é marcado pela procura da autoafirmação brasileira enquanto estado-nação. Buscava-se o perfil ideal de sociedade que iria constituir-se como brasileira, e nesse perfil os indígenas não estavam inclusos. Atrelase a isso a expansão do capital para o interior do país, buscando novas terras para dar uma utilização capitalista a essas. Foi nesse contexto que ocorreu a chacina contra os índios Kaingang em 1923 na então Vila da Serra da Pitanga, hoje munícipio de Pitanga - PR, sendo essa chacina marcada pela exurpação do território indígena com objetivos capitalistas. História contada e escrita na grande maioria por meio do senso comum, e carregado de preconceito, é a história contada pelo vencedor, por uma elite que se formou com base na concentração de terra, e essa apropriação fundiária ocorrendo em um curto período pós-conflito.
\end{abstract}

Palavras-chave: Chacina de 1923; Pitanga-PR; Kaingang; Ideologia do branqueamento; Territórios indígenas.

\begin{abstract}
:
The first decades of the twentieth century were extremely important for the formation of the current Brazilian social fabric, this period is marked by the search for Brazilian self-assertion as a nation-state, sought is the ideal profile of society that would be constituted as a Brazilian, and that profile indigenous were not included. Harnesses to this expansion of capital into the country, seeking new lands to give a capitalist use these. It was in this context that the massacre took place against the Kaingang Indians in 1923 in the then village of Serra da Pitanga, today municipality of Pitanga - PR, and this massacre marked by the usurpation of indigenous territory to capitalist purposes. This story, told and written in the vast majority through common sense, and full of prejudice, is the story told by the winner, by an elite that was formed based on the
\end{abstract}

\footnotetext{
* Universidade Estadual de Londrina. Mestrando em Geografia pela Universidade Estadual de Londrina. Email: kevo goncalves@hotmail.com

** Universidade Estadual de Londrina. Pesquisador do CNPq. Professor Doutor do Departamento de Geografia da Universidade Estadual de Londrina. E-mail: nilsoncesarfraga@pq.cnpq.br

*** Universidade Estadual de Londrina. Graduando em Geografia pela Universidade Estadual de Londrina. Email: mateuscavatorta@hotmail.com
} 
concentration of land, and that land ownership occurring in a short period post conflict.

Key words: Slaughter 1923; Pitanga-PR; Kaingang; Ideology bleaching; Indigenous territories.

\section{Introdução}

O mês de abril do ano de 1923 foi decisório para região central do Estado do Paraná, mais especificamente para o município de Pitanga-PR, pois foi nesse mês que ocorreu o maior conflito entre a população da etnia Kaingang e os recém-chegados colonos na então Vila Serra da Pitanga, conflito que culminou a morte de três colonos e de oitenta e cinco indígenas. Porém, mais importante do que o ocorrido em si, são as intencionalidades que motivaram o conflito, ou seja, o que se pretendia ter de resultado com a ocorrência desse fato.

Esse período foi marcado pelo racismo científico, teoria desenvolvida para legitimar a ideologia do branquamento, dessa forma julgando indígenas e negros como seres sem inteligência, por vezes considerados como seres ignorantes, sem cultura, sem a capacidade de raciocínio, atrelando-os assim com o subdesenvolvimento brasileiro. O Estado tratava as terras indígenas como terras de ninguém, um local onde havia um vazio demográfico, um local que não proporcionava lucros, criando-se, dessa forma, políticas que incentivaram o processo de povoamento da região com objetivo de dar um uso capitalista a ela, e também almejando branquear a população local, inserindo-a na política nacional de branquamento populacional.

Essa temática demonstra-se como complexa e polêmica, porém, deve ser debatida, já que cabe à ciência mais do que colaborar no processo de desenvolvimento socioeconômico de determinada comunidade, cabe a ela dar a possibilidade da recontagem da história oficial e de fortalecer economica, social e politicamente as comunidades indígenas, pois essas cada vez mais são enfraquecidas pela ganância do capital. Enfraquecimento este que se iniciou desde o momento dos primeiros contatos dos povos indígenas com os europeus e acentuou-se com a ideologia do branqueamento, ideologia que predominou por séculos e foi um dos fundamentos do processo de construção do território nacional brasileiro. Essa base ideológica era fundamentada por teorias científicas, isso para ser aceita pela comunidade científica e também para a nação 
ser aceita pela geopolítica mundial, no caso, a ideologia do branqueamento tinha como base o racismo científico. Tal ideologia foi uma das definidoras do que se pretendia com a instituição desse território e qual e como será a população inserida em seus limites, e dentro desse contexto os indígenas não estavam inseridos na população desejada, dessa forma comunidades indígenas inteiras foram exterminadas, levadas às margens da sociedade, sofrendo, ainda hoje, com a negligência estatal.

Será esse conflito resultado de um conjunto de políticas públicas que regiam o país no período do ocorrido? Seriam jogos de forças, na tentativa de enfraquecer uma elite que crescia na localidade? Seriam decisões políticas com o objetivo de "branquear" a população? Seriam decisões para desmantelar a comunidade indígena e justificar a ocupação de suas terras?

São diversas as questões que permeiam este artigo, e é por meio da abordagem delas que se buscará entender como se deram os processos que resultaram no conflito, e de como ela influenciou na atual condição da região central do Paraná.

\section{O espaço geográfico e o território como marco teórico}

Segundo Milton Santos (1985), para se compreender a organização espacial e sua evolução é necessário interpretar a relação entre estrutura, processo, função e forma: a estrutura refere-se ao modo como os objetos estão organizados, a natureza social e econômica de uma sociedade em um dado momento do tempo; o processo refere-se à construção das formas, uma ação visando algum objetivo qualquer; uma casa, um bairro, uma cidade e uma rede urbana são formas, formas espaciais de diferentes escalas; a função implica uma tarefa, atividade ou papel a ser desempenhado pelo objeto criado. Portanto, essa organização tem um aspecto exterior, visível - a forma - e desempenha uma atividade, a função. Habitar, viver o cotidiano, a vida em suas variadas facetas (trabalho, compras, lazer), visitar parentes e consumir em outras cidades são algumas das funções associadas, respectivamente, à casa, ao bairro, à cidade e à rede urbana. A relação entre forma e função é, em princípio, direta: uma determinada forma é criada para desempenhar uma ou várias funções.

Para Santos (1996), o espaço precisa ser considerado como totalidade: conjunto de relações realizadas mediante funções e formas apresentadas historicamente por processos 
tanto do passado quanto o presente. No começo era natureza selvagem, formada por objetos naturais que, ao longo da história, foram substituídos por objetos fabricados pelo trabalho social. O espaço é marcado pela presença desses objetos artificiais: fábricas, fazendas, estradas e caminhos, cidades, é determinado por esses acréscimos construídos pela atividade humana, modificando a natureza primitiva, dando lugar a uma "segunda natureza".

Complementando esta discussão sobre organização espacial, é pertinente citar Fraga (2010, p.73), quando o autor ressalta que:

\begin{abstract}
A produção do espaço é ação cotidiana do homem e aparece na forma de ocupação de um determinado lugar em momento histórico, em que a produção da cidade, por exemplo, aparece como manifestação espacial dos conflitos de interesses dos diversos agentes presentes nesse processo, associado ao desenvolvimento capitalista.
\end{abstract}

Diante desse conjunto teórico-conceitual sobre espaço geográfico e sua organização, pode-se analisar a organização do espaço pitanguense, que esteve vinculada a atividades econômicas de cunhos extensivo e extrativo e atividades agropecuárias, incorporando primeiramente o ciclo da erva-mate e do tropeirismo e, mais tarde, da madeira, no auge após a Segunda Guerra Mundial. A partir da riqueza gerada pelos referentes ciclos e dos migrantes atraídos pela riqueza natural da região, foram erguidos conjuntos de vilas, sendo estas estruturadas com a construção de moradias, igrejas, escolas, hospitais, comércio, dando origem a núcleos urbanos, que se tornaria a cidade de Pitanga.

Com a análise dos fragmentos históricos relacionados à Chacina ocorrida no município, é possível dizer que o processo de ocupação de Pitanga se deu de forma violenta, assim, o território é fruto de uma construção marcada pelo sangue derramado, em síntese, é um território político-jurídico, pois como afirma Haesbaert (2004, p.20):

Desde a origem, o território nasce com uma dupla conotação, material e simbólica, pois etimologicamente aparece tão próximo de terra-territorium quanto de terreo-territor (terror, aterrorizar), ou seja, tem a ver com dominação (jurídico-política) da terra e com a inspiração do terror, do medo-especialmente para aqueles que, com esta dominação, ficam alijados da terra, ou no "territorium" são impedidos de entrar. Ao mesmo tempo, por extensão, podemos dizer que, para aqueles que têm o privilégio de usufrui-lo, o território inspira a identificação (positiva) e a efetiva "apropriação". 
Há de se mencionar que desde a chegada dos primeiros colonizadores o território do atual município se caracterizou por uma porção de terra com apelo de utilização capitalista - em suma, de usurpação das terras ancestrais do Kaingang e da usurpação atual dessas terras pela mesma lógica capitalista. Pitanga e sua região geográfica sempre estiveram associadas à exploração capitalista e ao sangue que tal tipo de sistema gera sobre o solo dos seres humanos.

Não há uma forte bibliografia que aborda o conceito de território por meio de uma visão dos indígenas, e os trabalhos que propuseram enfocar nessa área não conseguiram propor uma teoria que seja aceita pela maioria dos pesquisadores da Geografia. Isso devido a não terem proposto uma teoria que abranja todas as etnias indígenas, tornando difícil que cada uma das diferentes etnias possua concepções de mundo aproximadas, porém, não idênticas. Dessa forma, torna-se ainda mais complexo compreender e formular uma teoria geral acerca das visões de território por meio das percepções dos indígenas.

A relação etnicista do indígena atrela-se e manifesta-se no espaço geográfico na formação de territórios, porém, a relação primitiva dos indígenas com o território desvincula-se da questão econômica e político-jurídico, é uma aproximação de topofilia, uma relação conceitual de lugar. Aqui considerando a posição de Claval (2001, p. 55), de que os lugares não tem somente uma forma e uma cor, uma racionalidade funcional e econômica. Eles estão carregados de sentido para aqueles que os habitam ou que os frequentam. No caso do indígena, o sentimento é ainda mais intenso, pois, para ele, o ser indígena não habita, ou não pertence àquele território, e, sim, faz parte da totalidade territorial.

Não se desvincula a relação poder-território, pois se assim fosse não seria território. Contudo a relação territorial do indígena não é gerido pela mesma lógica do poder que é exercido pelos Territórios Políticos Jurídicos ou Territórios Econômicos. A relação de poder sobre o espaço geográfico sobre qual uma determinada tribo indígena controla tem relações com a questão de sobrevivência daquele grupo, e do mantimento da história de seus antepassados que ali viviam.

É nessa perspectiva de diferenciação de concepções de mundos que se distinguem as noções de território entre indígenas e não indígenas, e ao abordar a questão territorial, nessa perspectiva, não se pode ignorar a questão etnicista, aqui desvinculando-se da visão 
promordialista e aproximando-se da visão goffmaniana, apontada por Streiff e Poutignatt (1998). Visão essa que demonstra a etnicidade como o sentimento de autorreconhecimento e autopertencimento em relação a um determinado grupo étnico, e essas relações manifestam-se de forma territorial. Além de não ignorar o patrimônio cultural dessas etnias, concordamos com Almeida (2007, p. 151) ao frisar que:

\footnotetext{
Um recurso cultural pode ser entendido como todo o fazer humano, incluindo bens materiais e bens imateriais [...] esse recurso, considerado como patrimônio cultural, é definido pelo conjunto de bens materiais, hábitos, usos, crenças e forma de vida cotidiana de todos os segmentos que compuseram e compõem as sociedades.
}

Ainda nessa lógica, Azevedo (1998, p. 149) traz que cultura e patrimônio compõem ambos acervos acumulado, cumulativos, às vezes, reelaborado, e sempre intransferível, de vivências locais das várias gerações, formando, assim, as identidades étnicas.

\section{A formação sócio espacial: frentes de ocupação do município de Pitanga}

A região onde está situada Pitanga apresenta características geomorfológicas e recursos naturais, possibilitando que diversos grupos pré-coloniais se instalassem nesse local e extraíssem os recursos necessários para sua subsistência. De acordo com pesquisas arqueológicas, identificaram-se três grupos indígenas que ocuparam a região: os Caçadores-Coletores, os ceramistas Jê e os ceramistas Guarani (SCHWENGBER; NOVASCO, 2011).

Algumas das características de cada grupo são mostradas a seguir:

- Caçadores-coletores: grupos nômades que se alimentavam de caça e de vegetais naturalmente disponíveis, explorando os ambientes abertos e as incipientes matas.

- Ceramistas Jê: migraram da região central do Brasil para as terras sul-americanas. Conhecidos por produzirem casas subterrâneas e confeccionar cerâmica. Esse grupo também representa os antepassados dos índios Kaingang.

- Ceramistas Guarani: ocuparam quase todo o território do Estado do Paraná, principalmente nos vales dos rios Paraná, Ivaí, Tibagi e Iguaçú. Caracterizam-se pela sua produção diversificada de vasilhas cerâmicas, entre elas vasos para conservação de bebidas, panelas, tigelas e potes. 
Segundo os estudos de Mota e Novak (2008), na bacia do Rio Ivaí há presença de material lítico com idade em torno de 8.000 anos, o que significaria que há existência de acampamentos indígenas na região por mais de oito milênios.

\begin{abstract}
No município de Manoel Ribas, na margem esquerda do rio Ivaí, no 3ำ planalto paranaense, encontram-se quatro abrigos, distante $6 \mathrm{~km}$ da linha Munhoz, que é banhada pelo rio Munhoz. O maior dos quatro abrigos, medindo 19,50m de comprimento, $9 \mathrm{~m}$ de profundidade e 4,50 de altura, foi escavado porque continha evidências arqueológica. Ele é dividido ao meio por um córrego que sai do interior e desemboca no arroio Munhozinho. Nos arredores do abrigo, na propriedade agrícola, coletou-se na superfície, material lítico lascado e revelado, segundo a autora apoiada em Igor Chmyz, que as coleções encontradas no local próximo ao abrigo pertenceriam à tradição Itararé e difeririam das coleções encontradas no interior do mesmo, que revelariam semelhanças com a tradição Casa da Pedra (SCHMITZ, 1988, p. 104).
\end{abstract}

Até o início do século XIX, a região dos campos gerais - de Guarapuava e de Palmas - era unicamente habitada pelos índios Kaingang, ramificação étnica proveniente do tronco linguístico Jê. Eles ocupavam toda a região do planalto paranaense, limitando seu território pelas vertentes orientais da Serra do Mar ao leste e pelas barrancas do Rio Paraná a oeste. Praticavam a agricultura de subsistência e tinham como principal recurso alimentar o pinhão, obtido da Araucária angustifólia (SCHWENGBER; NOVASCO, 2011).

O início do povoamento não indígena na Serra de Pitanga ocorreu a partir de meados do século XIX. Relatos indicam que no ano de 1844 já se haviam passado famílias de várias nacionalidades pelas terras que hoje são chamadas de Pitanga. No ano de 1897, após a Revolução Federalista ocorrida entre 1892 e 1894, migrantes de São Paulo e de Minas Gerais vieram para a região e se estabeleceram nas margens do Rio Batista. Há relatos também de que em meados dos anos 1900 já havia sinais de habitantes na região. $\mathrm{Na}$ época, essa região representava o espaço que atualmente se localiza os municípios de Campo Mourão e Guarapuava. A primeira capela na região foi construída em torno de 1910 em homenagem a Santa Ana. No ano de 1906, pelo o que se consta, foi aberta uma estrada entre Pitanga e Campo Mourão, onde havia um caminho muito precário, ou seja, um caminho tropeiro (EURICH, 2012.

Por volta do ano de 1847, vindos da Colônia Teresa Cristina se instalaram na região os irmãos Caillor, de origem francesa, que fundaram no planalto a povoação de Boa Ventura. Pouco tempo depois, instalaram-se na localidade denominada Tigre os migrantes 
Elias do Nascimento e Manuel Martiniano de Freitas. Já em julho de 1897, as famílias de Antônio Leonel Ferreira, João Luiz Pereira e José Martins Oliveira e outras famílias pioneiras chegaram na Serra de Pitanga e construíram suas moradias às margens do Rio Batista. A partir do ano 1916, houve uma contínua chegada a Serra da Pitanga de colonos e migrantes provenientes de diversas regiões do estado, principalmente da região de Prudentópolis. Alguns anos depois, ela se torna uma região criadora de porcos, ambos tocados a cavalo para serem vendidos no município de Ponta Grossa. Em 1918, já se verifica a presença de casas comerciais, ferreiros, carpinteiros, marceneiros e até um posto policial na região de Pitanga, fatos que comprovam um desenvolvimento em curto prazo da cidade. Em 1925, é criado o Distrito Judiciário, também época da instalação das primeiras repartições públicas do lugar, principalmente Cartório, Coletoria Estadual e Agência dos Correios. Em 1940, Pitanga já possuía cerca de 13.000 habitantes, refletindo também o rápido crescimento demográfico e desenvolvimento pelo qual o município estava passando. Os granjeiros da cidade e os lucros obtidos pela exportação de porcos para a cidade de Ponta Grossa foram os principais fatores que contribuíram para esse desenvolvimento (EURICH, 2012).

Pitanga foi uma cidade colonizada por europeus de vários países diferentes. Aos poucos foram chegando ucranianos, poloneses, italianos, alemães entre outros, explicando a diversidade cultural encontrada na cidade, com danças, músicas, arquiteturas e alimentação típicas de cada grupo (PITANGA, 2014).

A história da região central privilegiou por muito tempo a valorização dos colonizadores brancos. A participação dos povos indígenas muitas vezes não foi mencionada durante o processo de colonização. Por muito tempo, pensou-se que quando o "colonizador branco" chegou na região não havia ninguém ocupando este território, sendo a presença indígena invisível. Conhecia-se apenas a floresta constituindo um cenário selvagem que o progresso pretendia ocupar. Eram "terras de ninguém", não tinham dono. Esta versão da história contribuiu para a ideia de que havia nessa região um imenso "vazio demográfico", silenciando o fato de que, durante o processo de colonização, as comunidades indígenas dos Guaranis, Kaingang, Xetá já habitavam a localidade (TOMMASINO, 1995).

Os indígenas não aceitaram passivamente a presença do homem branco em seus territórios e se tornaram um obstáculo constante ao avanço da colonização. Os conflitos 
foram se tornando mais intensos envolvendo índios e coronéis, que eram uma espécie de chefes políticos da região. A intenção dos pioneiros era evitar que os índios continuassem a causar problemas aos exploradores da região. Aldeamentos foram construídos com esse objetivo, geralmente dirigidos por um religioso, que tinha a missão de ensinar aos índios os costumes dos brancos e transmitir a doutrina cristã. Viver em um aldeamento para os povos indígenas significava ter de aceitar também o modo de viver dos brancos e as regras que esses impunham a sua cultura (MOTA, 1994).

A história pode ter várias versões dependendo do olhar e do interesse de quem a conta. Destacou-se até aqui que, para os colonizadores não indígenas, essa terra era considerada um "vazio demográfico", ou "terras de ninguém". Mas e os povos indígenas que habitavam as florestas e que de um dia para o outro viram seus territórios sendo ocupados? O que dizem esses povos a respeito do processo de colonização e a consequente perda de seus territórios desde a chegada de outras civilizações? Essa resposta pode ser vista seus pensamentos na Declaração solene dos povos indígenas do mundo:

\begin{abstract}
Nós povos indígenas do mundo, unidos numa grande assembleia de homens sábios, declaramos a todas as nações: Quando a terra-mãe era nosso alimento, quando a noite escura formava nosso teto, quando o céu e a lua eram nossos pais, quando todos éramos irmãos e irmãs, quando nossos caciques e anciãos eram grandes líderes, quando a justiça dirigia a lei e sua execução, aí outras civilizações chegaram! Com fome de sangue, de ouro, de terra e todas suas riquezas, trazendo em uma 11 mão a cruz e na outra a espada. Sem conhecer ou querer aprender os costumes de nossos povos, nos classificaram abaixo dos animais. Roubaram nossas terras e nos levaram para longe delas, transformando em escravos "os filhos do sol". Entretanto, não puderam nos eliminar, nem nos fazer esquecer o que somos, porque somos a cultura da terra e do céu, somos de ascendência milenar e somos milhões e mesmo que nosso universo inteiro seja destruído, nos viveremos, por mais tempo que o império da morte!" (ZENUN; ADISSI, 1998, p.48).
\end{abstract}

Ainda hoje os povos Kaingang continuam assistindo a uma cena muito familiar desde os primeiros contatos com o "homem branco": seus territórios sendo ocupados pelo interesse capitalista. O progresso enxerga essas terras com os olhos do lucro, das possibilidades de conforto que podem trazer para a sociedade. Hoje esses indígenas sobrevivem das roças administradas pela FUNAI, das roças familiares, da venda de artesanato e da prestação de serviços para produtores rurais. Tendo perdido a maior parte de seus antigos territórios, os Kaingang ainda viram suas florestas serem devastadas pelas 
serrarias implantadas nas terras Kaingang e as melhores terras serem arrendadas para fazendeiros brancos (MOTA, 2000).

\section{Sobre as terras na serra de Pitanga: a chacina}

O principal motivo que desencadeou a revolta dos índios e o conflito entre eles e colonos foi o decreto no 294 de 17 de Abril de 1913, o qual privava os índios de algumas terras no Paraná e os obrigava a desapropriarem dessas. O governo do Paraná destinou as terras para fins de colonização, pois afirmava que havia um vazio demográfico nessa região e que necessitava de colonização, desconsiderando a existência da população indígena que habitavam o local. Com a expulsão, os índios foram prejudicados ao perderem suas terras, pois estavam acostumados com o seu modo de vida, tinham uma relação de subsistência com a terra, seu principal meio de produção. A partir dessa situação e com os colonos reduzindo suas reservas, os Kaingang iniciaram uma onda de saques aos sítios, furtando porcos para a alimentação (EURICH; 2010, p. 79). Quando pegos com o produto do furto, os índios eram chamados à presença de autoridades, sendo maltratados ou até mesmo mortos. Os caciques responsáveis pelos aldeamentos juntamente com os outros membros das aldeias decidiram iniciar uma revolta como única opção para recuperar suas terras e colocar fim às crueldades cometidas pelos colonos.

Segundo aponta a literatura regional, Camargo $(1999$, p. 29) no dia 1o de abril de 1923 os índios invadiram a sede da Vila da Pitanga. Não encontrando resistência, chegaram e saquearam as casas comerciais e domicílios. Manoel Lourenço e sua esposa Geraldina Alvez de Lima permaneceram no povoado, pois o Sr. Manoel acreditava que, por sua estima com os índios - muitas vezes fazendo papel de médico, receitando e dando remédios -, nada de mal fariam a sua família. Na tentativa de fuga, porém, são impedidos pelos Kaingang na saída do povoado e mortos a tiros e golpes de facão.

Ainda segundo Camargo (1999, p.33-34), os colonos Fernando Malko, Ataíde Ferreira, Gil Vaz de Camargo e Emílio Lantzmann continuaram no povoado como sinal de resistência. Armados, esperaram a noite, quando os índios e os "padres" reuniram-se na capela de Santana para beber e dançar com acordes de gaita. "Os índios acompanhados dos 'padres' dançam no interior da capela. [...] Fernando Malko observa: - Essa gente não é padre, não. Porque padre não dança, quanto mais dentro da igreja. É o demônio que está 
com esta gente". Os defensores da sede entraram na capela e, antes que os índios pudessem revidar, atiraram contra eles. Um dos "padres" foi morto. "Seus cabelos são loiros. Aparenta uns 20 anos". Não tendo condição de detê-los e com as Winchesters descarregadas, os colonos recuaram para as margens do Rio Ernesto. Emílio foi, então, morto pelos índios. "Não tivesse Emílio Lantzmann e seus companheiros na tarde do dia 5 de Abril de 1923 procedido com rigor contra os índios, matando inclusive os 'padres' que os lideravam, a sua revolta teria se constituído numa verdadeira guerra e com inúmeras vítimas".

Depois desse confronto, os índios kaingang resolveram recolher seus mortos e voltaram para a localidade de Santidade, à margem esquerda do rio Barra Preta. Luiza Petrechen relata no livro de Vaz que: "A igreja foi queimada porque não prestou mais de tanto sangue de índio derramado" (EURICH e SEBRIAN, 2010, p.28). O conflito terminou com um saldo de muitas vidas perdidas, tanto de índios quanto de colonizadores.

Atualmente, os Kaingang encontram-se assentados na terra indígena Marrecas, situada à margem direita do rio Marrecas, entre os municípios de Turvo e Guarapuava (a aproximadamente $70 \mathrm{~km}$ de Pitanga).

Com esses fragmentos históricos, é possível dizer que o processo de ocupação de Pitanga se deu de forma violenta, portanto, o território é fruto de uma construção marcada pelo sangue derramado. Em síntese, é um território político-jurídico, hoje marcado pelo sangue do passado, ou seja, Pitanga é uma terra manchada de sangue, e esse massacre é fruto de uma ideologia maior, que será explanado a seguir.

\section{Ideologia do branqueamento e a expansão do capital}

O processo de construção de um território nacional tem que estar fundamentado nas bases ideológicas, e essa base ideológica deve estar fundamentada em teorias científicas para ser aceita pela geopolítica mundial, a qual define o que se pretenderá com a instituição desse território e qual e como será a população inserida em seus limites. A chacina dos Kaingang ocorre em um período em que o Estado brasileiro estava em na busca pela sua autoafirmação como estado-nação, e nesse mesmo período a ideologia do branqueamento estava no seu auge. Porém para entender o que é a ideologia do 
branqueamento, antes devemos compreender o que é o termo ideologia. Segundo Chauí (1980, p. 36):

A ideologia consiste precisamente na transformação das idéias da classe dominante em idéias dominantes para a sociedade como um todo, de modo que a classe que domina no plano material (econômico, social e político) também domina no plano espiritual (das idéias).

Dessa forma, compreendido o que é o termo ideologia, parte-se para o entendimento do significado do termo branqueamento, o qual, Bernardino (2002, p.253) define como a:

Diminuição da população brasileira negra em relação à população branca devido, entre outros fatores, a uma taxa de natalidade e expectativa de vida mais baixas e, por outro lado, devido ao fato de a miscigenação produzir uma população gradualmente mais branca.

A ideologia do branqueamento teve por fudamentação o racismo científico, sendo esse baseado nas ideias do darwinismo social, no qual se explicava que uma determinada sociedade era mais desenvolvida que a outra devido a sua etnia, ou seja, sua condição física, como a cor da pele, textura do cabelo. Nesse período, segundo Bolsanello (1996, p 154), houve pesquisas da genética, psicologia, antropologia e sociologia para confirmar e autenticar essa ideologia. Dessa forma, empregnou-se a ideologia do branqueamento no Brasil, afirmando que o subdesenvolvimento do Estado brasileiro estava atrelado a grande quantidade de negros e indígenas presentes no território brasileiro. Nesse sentido, Oliveira (2008, p.07) afirma que:

O racismo científico teve sua época áurea entre 1870 a 1930, ele procurava explicar biologicamente as características dos homens. Era considerado científico porque foi produzido pela antropologia e pela sociologia, pelas ciências do século XIX. [...] A adoção pela elite brasileira das teorias do chamado racismo científico, teve início em 1870 e tornaram-se amplamente aceitas entre as décadas de 1880 e 1920.

Dessa forma, o Estado brasileiro necessitava de respostas para o seu subdesenvolvimento brasileiro, e assim o seu atraso - frente a outras nações - não fora nesse momento diagnosticado, considerando o seu passado e suas práticas econômicas ou sociais, mas pelas características de seu povo (SANTOS, 2009). Incentivou-se, portanto, a 
vinda dos imigrantes europeus para o Brasil, sendo esses considerados agentes tranformadores do Brasil, conforme afirma Hauresko (2009, p. 245):

Para o governo, o imigrante europeu deveria ser um agente modernizador da sociedade e da economia brasileira, dado que era detentos de novas experiências agrícolas e de criação, com técnicas artesanais novas, com outros hábitos de vida, enfim, para ser o agente transformador da sociedade brasileira em formação e, sobretudo, esperava-se que este contribuísse para tirar o país da situação de atraso a que o sistema colonial o tinha relegado.

Ainda tem-se o decreto de 28 de junho de 1980, que confirma o quanto era desejável ao Estado brasileiro a migração dos europeus para o Brasil e indesejados os asiáticos e negros.

Decreto de 28 de junho de 1890 concede que:

\begin{abstract}
É inteiramente livre a entrada, nos portos da República, dos indivíduos válidos e aptos para o trabalho [...] Excetuados os indígenas da Ásia ou da África, que somente mediante autorização do Congresso Nacional poderão ser admitidos [...] Decreto-Lei n. 7967 assinada por Getúlio Vargas em 18 de setembro de 1945, regulando a entrada de imigrantes de acordo com a necessidade de preservar e desenvolver na composição étnica da população, as características mais convenientes da sua ascendência européia (NASCIMENTO, 1978, apud SILVA, DINIZ, 2010, p.04).
\end{abstract}

Porém, os povos indígenas mesmo não incluído nesse decreto eram vistos com o mesmo olhar pelo Estado, também sendo culpado pelo subdesenvolvimento do país, conforme é evidenciado por Hofbauer (2003, p. 71):

\begin{abstract}
É importante destacar que esta construção ideológica que tendia a igualar o "ser escravo" com a "cor negra" não era usada exclusivamente para caracterizar as populações do continente africano. Enquanto os indígenas do Novo Mundo foram vítimas de escravizações, eles eram qualificados não apenas como "índios" ou "gentios", mas também eram chamados simplesmente de "negros". A denominação de "negro" para indígenas foi inicialmente usada também pelos jesuítas que chegaram a apoiar "guerras justas" contra populações indígenas.
\end{abstract}

Justificavam, dessa forma, a chacina cometida contra os indígenas, pois era um meio de alcançar o desenvolvimento do país. Foi no mesmo ano da chacina de 1923, que se constituiu no Brasil a Liga Brasileira de Higiene Mental, com o objetivo inicial de melhorar a assistência psiquiátrica, mas tais metas foram desviadas para enfatizar programas de prevenção eugênica, baseados inclusive na psiquiatria nazista. Os médicos assumiram o 
papel de mandatários da ordem social e endossaram os preconceitos culturais da época (BOLSANELLO, 1996, p. 161).

Outros cientístas, tal como o sociólogo Francisco de Oliveira Viana, afirmavam que tanto os negros quanto os índios eram totalmente refratários à civilização, e que os mestiços conservavam qualidades da raça inferior, sendo desiquilibrados e não tendo o desejo de ascender, de sair da sua condição de pária (BOLSANELLO, 1996, p. 159).

Da mesma forma, demais cientístas defendiam a ideologia do branqueamento, conforme vemos na afirmação de Romero (1880):

Pela seleção natural, todavia, depois de prestado o auxílio de que necessita, o tipo branco irá tomando a reponderância até mostrar-se puro e belo como no velho mundo. Será quando já estiver de todo aclimatado no continente. Dois fatos contribuirão largamente para tal resultado: - de um lado a extinção do tráfico africano e o desaparecimento constante dos índios, e de outro a emigração européia (apud HOFBAUER, 2003, p. 108).

Seguindo a mesma linha de pensamento, Diwan (2007, p. 87-97) afirma que:

O projeto engendrou um quadro social, político, histórico que, entre outros elementos, legitimou a idéia da inferioridade da população negra e da superioridade da população branca, não apenas pelo elemento da escravidão, mas pela tentativa de tornar o Brasil um país de brancos e, portanto, um país desenvolvido e limpo. No que se refere à política eugenista havia a intenção de "purificar a raça" e aperfeiçoar o homem a cada geração. Esse aperfeiçoamento pautava-se na extinção de todos os "tipos" contrários ao ideal de "belo" e de "força".

Portanto, é uma ideologia que utilizou a ciência para legitimar o preconceito. Observa-se que estavam lançadas as bases científicas do preconceito racial e a legitimação das desigualdades sociais em nome da democracia (BOLSANELLO, 1996, p. 159). Essa ideologia do branqueamento nos revela suas principais características no tecido social brasileiro, sendo essa marcada profundamente pela desigualdade social, a mesma que tornou justa a chacina de 1923 contra os Kaingang, e ainda legitíma o massacre que ocorre com as etnias indígenas no território brasileiro, tudo isso atrelado à busca da expansão do capital, nesse sentido, Haesbaert (2004, p.57) afirma que:

Hoje, na maior parte dos lugares, estamos bem distantes de uma concepção de território como "fonte de recursos" ou simples "apropriação da natureza" em 
sentido estritos. Isto não significa, contudo [...] que essas características estejam superadas. Dependendo das bases tecnológicas do grupo social, suas territorialidades ainda podem carregar marcas profundas de uma ligação com a terra, no sentido físico do termo.

Ainda nesse sentido, Fajardo (2008, p. 29) afirma que a abordagem econômica do território envolve um jogo de forças no qual o poder, exercido pelo Estado ou por empresas, não ignora a natureza enquanto recurso. Desse modo, pode-se entender que o Estado buscou dar uma utilização a essas terras com o propósito de obter lucratividade sobre elas, em que pouco se arrecadava as mesmas, e não considerando a ligação que os indígenas tinham (e têm) com a terra onde habitam.

Em consequencia da Primeira Guerra Mundial, que ocorria nesse mesmo período, houve a necessidade de aumentar a exploração de madeira no mundo colonial e excolonial, abrindo perspectivas para a comercialização do dito pinheiro do Paraná, ou seja, da floresta de araucária e das espécies nobres de madeira existente nela, pois os preços da madeira subiram no mercado internacional em decorrência do conflito mundial (FRAGA, 2010 , p. 125). No entanto, nesse momento de guerra, não houve a extração da madeira em grandes quantidades na região, deixando-a como uma reserva, mas não para preservação biológica e cultural dos indígenas, e, sim, como uma reserva de madeira, pronta para a exploração De fato isso ocorreu, como pode ser visto na fala de Silva $(2007$, p. 63):

\begin{abstract}
Assim, a organização do espaço esteve vinculada a atividades econômicas de cunhos extensivo e extrativo [...] incorporando, em paralelo, a extração da erva mate e, mais tarde, da madeira, esta com auge após a Segunda Guerra Mundial. Nesse sentido, convém sublinhar que, de forma geral, a economia da região esteve sempre associada a exploração de algum recurso da natureza que foi utilizada, muitas vezes, de forma predatória e rudimentar.
\end{abstract}

Ou seja, essa apropriação de terras veio apresentar uma maior importância econômica no futuro, foi quando se instalaram diversas madeireiras na região, formando assim diversas pequenas vilas e fortalecendo ainda mais uma elite que se formava, sendo essa altamente beneficiada com o conflito com os indígenas, desestabilizando a comunidade Kaingang e a tornando mais frágil nos embates da vida cotidiana. Fazendo uma análise dos sobrenomes envolvidos diretamente no ocorrido, de imediato associam-se às famílias que integram a atual elite pitanguense, composta de grandes (lati)fundiários e proprietários ou ex-proprietários de madeireiras, os quais conseguiram concentrar tal 
riquezas no período após o conflito com os Kaingang. Essa elite, que no momento estava se formando, mostrava-se, e ainda se mostra, com aspectos de uma ideologia conservadora. Concordamos com Silva (2007, p. 17) quando esse afirma que:

\footnotetext{
Os territórios conservadores se constituíram historicamente, procedentes de formações sociais mais arcaicas, estes são justificados, também, por relações políticas conservadoras, cuja articulação pode ser representada por meio de redes sociais de poder. Então, chegou-se um aspecto. Conservadoras são as relações políticas e não a sociedade.
}

A mesma autora ainda menciona que a sociedade apresenta-se conservadora como reflexo das ações de parte da sociedade, e não da sociedade como um todo (SILVA, 2007) Nesses trechos, a autora refere-se ao município de Guarapuava, porém, as sociedades guarapuavana e pitanguense apresentam enormes semelhanças em questões culturais, isso devido a proximidades entre eles, o processo de formação dos núcleos urbanos serem parecidos, e sem ignorar que o município de Pitanga desmembrou-se administrativamente da comarca de Guarapuava apenas no ano de 1944, portanto, ainda no ano de 1923 a região onde ocorreu o conflito pertencia à comarca supracitada.

O processo de formação de uma elite na nova vila não era bem visto por Guarapuava, a elite guarapuavana não via vantagens em dar continuidade a essa vila, que posteriormente poderia fortalecer-se e buscar autonomia. De tal modo, Guarapuava perdendo uma considerável quantia de terras com abundantes reservas de mata nativa, relutou em permitir o avanço socioeconômico pitanguense. Eurich (2012) faz uma análise sobre o processo judicial que ocorreu após o conflito e destaca que:

\footnotetext{
A absolvição dos réus, mesmo com tantas testemunhas de acusação e a forma abrupta com que termina o processo, traz dúvidas sobre as intenções da elite guarapuavana da época que o julgou e não fez justiça a população de Pitanga [...]. Não queriam os guarapuavanos desentendimento com os indígenas por causa do território de pastagem do Campo Moura, seria melhor deixá-los livres e aldeados no Ivaí? (EURICH, 2012, p. 108).
}

A autora traz a indagação de que os guarapuavanos não queriam desentendimento com os indígenas, porém, para eles seria vantajoso desestabilizar e desmoralizar os indígenas, assim poderiam justificar a tomada de posse de suas terras. Essa elite, além de ambiciosa, mostrava-se extremamente preconceituosa, assim como a maior parte da 
sociedade brasileira na época. Isso é evidenciado, principalmente, pelas políticas que incentivaram a vinda de imigrantes europeus para o Brasil, objetivando branquear a população do país, pois se considerava o negro e o índio como seres atrasados. Há de se considerar que esse processo de atração foi mais do que um fator econômico, foi puramente preconceituoso, baseado no racismo científico.

\section{Considerações finais}

A análise aplicada sobre esse tema teve como base pesquisas documentais e bibliográficas, que apontam algumas possibilidades de verificações, entre o in loco e o parco marco teórico sobre a chacina de Pitanga. Este artigo procurou explanar os motivos e as intenções da chacina, dando enfoque ao processo de invasão do território Kaingang e a ideologia que legitimou esse massacre, além de abordar sobre a história da ocupação do município, mencionando a ocupação indígena e não indígena pelo qual passou a região.

Passados 93 anos da chacina dos índios Kaingang, ainda hoje pouco se sabe sobre os verdadeiros objetivos envoltos nesse ocorrido. Ao fazer uma análise geográfica sobre o ocorrido e sobre suas consequências na atual condição da região central do Paraná, consegue-se atrelar a concentração fundiária e a localização dos latifúndios com o antigo território indígena, sendo este próximo de rios e em terrenos mais planos.

A chacina é um dos resultados de uma conjuntura política, econômica e cultural que predominava na época, cuja matriz de pensamento acredita-se seguir até os dias atuais, pois comumente é noticiada a morte de indígenas para a posse de suas terras.

O objetivo da chacina e da invasão dos territórios dos Kaingang não era transformar os povos indígenas em mercado consumidor, pois até então a sociedade branca considerava a região como vazia, sem sociedade, portanto, sem pessoas, mas cobiçavam nas terras indígenas a exploração da madeira e da erva-mate.

A região central do Paraná é atualmente uma das mais pobres do Paraná, possuindo uma elevada desigualdade social em todos os municípios, sendo que alguns deles possuem os mais baixos índices de desenvolvimento humano do estado. Esses dados se concretizam devido à concentração fundiária, à concentração de renda, à violência, à falta de infraestrutura, à impossibilidade de geração de trabalho, à renda e riqueza para um grupo maior de cidadãos; por meio de tais dados, a região ficou conhecida por ser um "bolsão da 
pobreza do Paraná". Por arremate, acredita-se ser difícil ter um bom nível de desenvolvimento quando se é cercado por uma sociedade conservadora e, quando não, preconceituosa e que omite a própria história, fazendo injustiças antes mesmo de o município de Pitanga possuir sua emancipação político-jurídica.

O conceito de território na percepção do indígena diferencia-se da noção tradicional da Geografia, atrela-se à questão da etnicidade diferente da visão tradicional para o indígena - o ser índio também é solo, também é animal, também é vegetal, também é água, não se desvincula o ser humano do ser natureza - porém, também não se desvincula o poder exercido por determinada tribo em seu território. Os conflitos territoriais dos indígenas não liga-se à questão do possuir solo, e sim de sua sobrevivência depender daquele território.

As atuais condições em que os indígenas estão submetidos são resultados de uma conjuntura política, econômica e cultural que predominava e ainda predomina no Brasil, cuja matriz de pensamento acredita-se seguir até os dias atuais, pois comumente é noticiado a morte de indígenas para a posse de suas terras ou simplesmente por preconceito. Tal situação é precária tanto nas comunidades indígenas rurais quantos nas urbanas, tanto para os indígenas aldeados quanto para os desaldeados, sendo que ambos sofrem com a negligência estatal por séculos, em que se busca omitir a realidade, nega-se dar voz a esses povos que sofrem com um genocídio desde que os primeiros europeus chegaram no solo que pertencem originalmente a estes povos, mas que os é negado.

A luta histórica dos indígenas não é apenas para aumentar a arrecadação e assim melhorar as condições de vida nas comunidades, a luta dos indígenas é para manter-se vivos, pois sem seu território dificilmente a comunidade sobreviverá, e vai além. Além disso, a vida dos indígenas está em constante ameaça, e aqui não se refere-se apenas à vida cultural, e sim biológica, e recontando a história desses povos, fazendo justiça, dando voz a eles, dará força e novas condições para essas comunidades.

\section{Referências}

ALMEIDA, M. G. Desafios e possibilidades de planejar o turismo cultural. In: SEABRA, G. (Org.). Turismo de base local: identidade cultural e desenvolvimento regional. João Pessoa: Ed. Universitária UFPB, 2007. p. 151-168. 
AZEVEDO, J. Turismo, cultura e patrimônio. In: CORIOLANO, L. N. M. T. (Org.). Turismo com ética. 2. ed. Fortaleza: UECE, 1998. p. 148-164.

BERNARDINO, J. Ação afirmativa e a rediscussão do mito da democracia racial no Brasil: Revistas de Estududos Afro-Asiáticos, Rio de Janeiro, v. 24, n. 2, p. 247-273, 2002.

BOLSANELLO, M. A. Darwinismo social, eugenia e racismo científico: sua repercussão na educação e Sociedade Brasileira. Revista Educar, Curitiba, n. 12, 1996.

CAMARGO, M. B. Abril Violento: A revolta dos índios Kaingangues. Curitiba: Base, 1999.

CHAUÍ, Marilena. O que é ideologia. São Paulo: Ed. Brasiliense, 1980.

CLAVAL, P. A geografia cultural. Florianópolis: Ed. UFSC, 2001.

DIWAN, P. Raça pura: uma história da eugenia no Brasil e no mundo. São Paulo: Contexto, 2007.

EURICH, G. O índio no banco dos réus: historicizando o conflito entre índios Kaingang e colonos na Vila Pitanga (1923). 2012. Dissertação (Mestrado em História) - Universidade Estadual de Maringá, Maringá, 2012.

; SEBRIAN, R. N. N. Índios Kaingáng e colonizadores: versões do conflito na Vila da Pitanga, 1923. Revista Tempo, Espaço e Linguagem, Irati, v. 1, n. 1, p. 23-43, jan./jul. 2010.

FAJARDO, S. Territorialidades corporativas do rural paranaense. Guarapuava: Unicentro, 2008.

FRAGA, N. C. Vale da morte: o contestado visto e sentido entre a Cruz de Santa Catarina e a Espada do Paraná. Blumenau: Hemisfério Sul, 2010.

(Org.). Territórios e fronteiras:(re)arranjos e perspectivas. Florianópolis: Insular, 2011.

HAESBAERT, R. O mito da desterritorialização: do "fim dos territórios" a multiterritorialidade. Rio de Janeiro: Bertran Brasil, 2004.

HAURESKO, C. O estabelecimento de colonos no estado do Paraná e os fatores limitantes ao desenvolvimento das colônias agrícolas. In: VESTENA, L. R. et al. (Org.). Saberes geográficos: teorias e aplicações. Guarapuava: Unicentro, 2009.

HOFBAUER, A. Conceito de "raça" e o ideário do "branqueamento" no século XIX: teoria e pesquisa, São Paulo: Universidade Federal de São Carlos, 2003.

MOTA, L. T. As guerras dos índios Kaingang: a história épica dos índios Kaingang no Paraná (1769-1924). Maringá: EDUEM, 1994. 
2000.

(Org.). As cidades e os povos indígenas: mitologias e visões. Maringá: EDUEM,

; NOVAK, E. S. Os Kaingang do vale do rio Ivaí PR: história e relações interculturais. Maringá: EDUEM, 2008.

OLIVEIRA, I. M. A. A ideologia do branqueamento na Sociedade Brasileira. 2008. Trabalho de Conclusão de Curso (Programa de Desenvolvimento Educacional) - Universidade Estadual do Norte do Paraná, Santo Antonio do Paraíso.

PITANGA. Prefeitura Municipal. Historia de Pitanga. Disponível em:

<http://www.pitanga.pr.gov.br>. Acesso em: 18 jul. 2014.

SANTOS, M. Espaço e método. São Paulo: Nobel, 1985.

A natureza do espaço. São Paulo: Hucitec, 1996.

SANTOS, N. N. S. Ideologia do branqueamento, ideologia da democracia racial e as políticas públicas direcionadas ao negro brasileiro. Revista Urutágua, Maringá, v. 19, p. 173-187, 2009.

SCHMITZ, P. I. As tradições ceramistas do planalto sul-brasileiro. São Leopoldo: Instituto Anchietano de Pesquisas, 1988. Documentos, n. 2, p. 75-130.

SCHWENGBER, V. L.; NOVASCO, R. V. Arqueologia no Vale do Pitanga: resgate arqueológico e educação patrimonial nas imediações da área de implementação da PCH Itaguaçu. Tubarão: Copiart, 2011.

SILVA, E. J. N. A.; DINIZ, L. M. Questão etnicorracial: uma problematização sobre a lei 10.639/03 e seus desdobramentos. In: CURSO DE FORMAÇÃO CONTINUADA EM RELAÇÕES ÉTNICO-RACIAIS E CULTURA AFRO-BRASILEIRA PARA REDE ESTADUAL DE ENSINO, 1., 2010. Anais... Londrina, 2010.

SILVA, M. Análise política do território: poder e desenvolvimento no centro-sul do Paraná. Guarapuava: Edunicentro, 2007.

TOMMASINO, K. A história dos Kaingáng da bacia do Tibagi: uma sociedade jê meridional em movimento. 1995. Tese (Doutorado em Antropologia) - Faculdade de Ciências Humanas da Universidade de São Paulo, São Paulo, 1995.

ZENUN, K. H.; ADISSI, V. M. A. Ser índio Hoje: tensões territoriais. São Paulo: Edições Loyola, 1998. 